Ching-Yue Yang MD, ${ }^{*}$ Hsiang-Ning Luk MD PhD, ${ }^{\dagger}$ Shu-Ying Chen Ms, ${ }^{\ddagger}$ Wun-Chin Wu Pho, ${ }^{\ddagger}$ Chok-Yung Chai $\mathrm{MD}^{\mathrm{PhD}} \mathrm{D}^{\ddagger}$

\section{Propofol inhibits medullary pressor mechanisms in cats}

Purpose: Propofol may cause hypotension and the mechanism is complex. The present study was designed to determine the direct actions of propofol in medulla of cats.

Methods: Mean systemic arterial pressure (MSAP), heart rate (HR) and cardiac contractility ( $d p / d t)$ were compared before and after administration of propofol through the femoral vein $\left(2.3\right.$ or $\left.4 \mathrm{mg} \cdot \mathrm{kg}{ }^{\prime}\right)$, vertebral artery ( $1 \mathrm{mg} \cdot \mathrm{kg}^{\prime}$ ) or the lateral cerebral ventricle $\left(0.5 \mathrm{mg} \cdot \mathrm{kg}^{\prime}\right.$ ) in eight anaesthetized cats. To study the direct effect of propofol in medulla, pressor areas of the dorsomedial medulla (DM) and rostral ventrolateral medulla (RVLM). or the depressor area of the caudal ventrolateral medulla (CVLM) were first identified with electrical stimuli and then confirmed by pressure microinjection of glutamate (Glu, $0.25 \mathrm{M}, 30 \mathrm{nl}$ ) via a multibarrel-micropipette in 28 cats. One hour later, propofol $(0.001 \%, 50 \mathrm{nl})$ was microinjected at the same site. Electrical stimulation and Glu were applied again to compare changes of SAP. HR and dp/dt with that of the control.

Results: Propofol dose-dependently decreased SAP, HR and cardiac contractility. The percent increase of MSAP induced by Glu were reduced by propofol in DM $(59 \pm 3 \%$ vs $13 \pm 2 \%, n=11, P<0.01)$ or in RVLM (56 $\pm 4 \%$ vs $18 \pm 2 \%, n=9, P<0.01)$. In CVLM, propofol slightly but not significantly increased the depressor responses elicited by Glu $(-27 \pm 2 \%$ vs $-33 \pm 3 \%, n=5, P>0.05)$.

Conclusion: Our results show that propofol principally inhibits the vasomotor mechanism in the dorsomedial and ventrolateral medulla to effect its hypotensive actions.

Objectif : Le propofol produit de l'hypotension par un mécanisme complexe. Cette étude avait pour objectif de délimiter sur le bulbe du chat l'activité directe du propofol.

Méthodes : La pression artérielle systémique moyenne (PASM), la fréquence cardiaque (FC) et la contractilité cardiaque (dp/dt) ont été comparées avant et après l'injection de propofol dans la veine fémorale $(2,3$ et 4 $\left.\mathrm{mg} \cdot \mathrm{kg}^{\prime}\right)$, l'artère vertébrale (I mg.kg') et le ventricule cérébral latéral $\left(0,5 \mathrm{mg} \cdot \mathrm{kg}^{-1}\right)$ chez six chats anesthésiés. Pour étudier les effets bulbaires directs du propofol, les zones vasopressives dorsomédiane (DM) et ventrolatérale rostrale (BVLR) bulbaires, ou la zone vasodépressive ventrolatérale caudale (BVLC) bulbaire ont d'abord été identifiées par stimulation électrique et confirmées par micro-injection sous pression de glutamate (Glu $0.25 \mathrm{M} .30 \mathrm{ml}$ ) à l'aide d'une micropipette à plusieurs barillets chez 28 chats. Une heure plus tard, du propofol $(0,001 \%, 50 \mathrm{nl})$ était injecté au même site. L'électrostimulation et Glu étaient appliqués encore une fois pour comparer les changements de PAS, le FC et de dp/dt avec ceux du contrôle.

Résultats : Dépendamment de la dose, le propofol diminue PAS. FC et $d p / d t$. En pourcentage, l'augmentation de PASM induite par Glu était réduite par le propofol dans DM $159 \pm 3 \%$ vs $13 \pm 2 \%, n=11, P<0,01$ ) ou dans BLVR $(56 \pm 4 \%$ vs $18 \pm 2 \%, n=9 . P<0,01)$. Dans BLVM. le propofol a augmenté légèrement mais non significativement les réponses vasodépressives induites par Glu $(-27 \pm 2 \%$ vs $-33 \pm 3 \%, n=5, P<0,05)$.

Conclusion : Nos résultats montrent que l'action hypotensive du propofol est causée par l'inhibition du mécanisme vasomoteur au niveau des zones bulbaires dorsomédiane et ventrolatérale.

From Department of Anacsthcsiology, Chang Gung Mcmorial Hospital, at Kweishan, Taoyuan, ${ }^{*}$ Department of Pharmacology, National Defense Medical Center, ${ }^{\dagger}$ and Neuroscience Division, Institute of Biomedical Science, Academia Sinjca, ${ }^{\ddagger}$ Taiwan, R.O.C.

Address correspondence to: Chok-Yung Chai, MD Ptw, Neuroscience Division, Inscitute of Biomedical Sciences, Academia Sinica, Taipci, Taiwan, ROC. Phone: 886-2-789-9105; Fax: 886-2-782-5573.

Presented in part at the Annual Mecting of the Canadian Anaesthetists' Society, Montreal, Canada.

Accepted for publication April 1.3, 1997. 
$\mathrm{P}$ ROPOFOL (2,6-diisopropylphenol, Diprivan ${ }^{\mathrm{TM}}$ ), is an intravenous anaesthetic commonly used in clinical practice that produces few adverse effects. In some elderly or critically ill patients, however, propofol may decrease cardiac output, and cause hypotension and bradycardia. ${ }^{1}$ The mechanism responsible for the propofol-induced hypotension has not been well-defined. The following may contribute to these actions of propofol: direct peripheral vasodilatation, ${ }^{2,3}$ decrease in sympathetic tone, ${ }^{4,5}$ resetting of baroreflex sensitivity, ${ }^{4}$ and direct negative chronotropic and inotropic actions. ${ }^{6,7}$ The reduction in sympathetic activity may be central in origin. In rats, propofol reduced the sympathetic renal nerve activity and antagonized the inhibitory action of glycine in the rostral ventrolateral medulla (RVLM). ${ }^{8,9}$ However, whether propofol exerts direct actions on other medullary areas for cardiovascular integration besides the RVLM needs further investigation.

In addition to the RVLM, other regions that participate in the cardiovascular integration in the medulla include the pressor dorsomedial medulla (DM), ${ }^{10}$ and the depressor caudal ventrolateral medulla (CVLM). ${ }^{11}$ These regions contain neuronal bodies effecting integration of resting blood pressure, blood flow and heart rate via increased or decreased activity of the sympathetic nervous system. Meanwhile, excitatory and inhibitory amino acids, such as glutamate (Glu), gamma aminobutyric acid (GABA) and glycine, have been demonstrated to serve as neurotransmitters or modulators in neurons of these structures. ${ }^{12-14}$ In addition, microinjection of Glu at the DM and RVLM produced not only cardiovascular but also non-cardiovascular effects (motility of the urinary bladder). ${ }^{10,15}$ The present study is in an attempt to investigate whether propofol directly affects the Glu-elicited cardiovascular responses in these pressor and depressor areas in the medulla.

\section{Methods}

Experiments were performed in 36 cats of either sex $\left(1.8-4.2 \mathrm{~kg}\right.$ ) anaesthetized by a mixture of $40 \mathrm{mg} \cdot \mathrm{kg}^{-1}$ -chloralose and $400 \mathrm{mg} \cdot \mathrm{kg}^{-1}$ urethane administered intraperitoneally. The trachea was intubated to allow spontaneous respiration or artificial ventilation through a respirator (Harvard apparatus, Ma, USA). In the latter case, the animals were paralyzed with 2 $\mathrm{mg} \cdot \mathrm{kg}^{-1}$ gallamine triethiodide $i v$ and respiratory rate and the tidal volume were adjusted to an end expiratory $\mathrm{CO}_{2}$ concentration of 3.5-4.0\%, monitored with a capnograph (Capnograph IV, Gould, Ohio, USA). Rectal temperature was maintained at $37 \pm 0.5^{\circ} \mathrm{C}$ by a homeothermic blanket system. Polyethylene catheters were inserted into the right femoral vein for adminis- tration of drugs or fluid, and into the right femoral artery for monitoring the systemic arterial pressure (SAP), mean SAP (MSAP), heart rate and $d \mathrm{p} / d \mathrm{t}$, an indirect index of cardiac contractility. All data were recorded on a polygraph (2800S, Gould) and stored on a digitized videotape recorder (Neuro-corder DR886, Neuro Data Ins., NY, USA).

In order to determine the central or peripheral sites of action of propofol, the cardiovascular variables were compared by administration of propofol via different routes, i.e., femoral vein, vertebral artery, or left lateral cerebral ventricle. The same volume of solvent for propofol (Intralipid ${ }^{\mathrm{TM}}$ ) was also administered from the respective routes for comparison. For peripheral injection, propofol $\left(2,3\right.$ and $\left.4 \mathrm{mg} \cdot \mathrm{kg}^{-1}\right)$ was administered into the femoral vein. For administration of propofol into the vertebral artery, the left vertebral artery was dissected free through a transaxillary approach. A catheter was inserted into the left subclavian artery distal to the bifurcation of the common carotid artery for subsequent intravertebral arterial injection. All other branches of the subclavian artery, including common carotid artery except the vertebral artery, were ligated. Propofol $\left(1 \mathrm{mg} \cdot \mathrm{kg}^{-1}\right)$ or the same volume of its solvent was administered into the vertebral artery. For intra-cerebroventricular injection, the head of the cat was immobilized in a stereotaxic apparatus (David-Kopf, Tujunga, CA, USA). The left lateral cerebral ventricle was stereotaxically located and cannulated with a $25 \mathrm{G}$ spinal needle. ${ }^{16}$ Propofol $(0.5$ $\mathrm{mg} \cdot \mathrm{kg}^{-1}$ ), or the same volume of its solvent, was administered directly into the ventricle.

The possible direct actions of propofol in the cardiovascular-reactive areas of medulla were determined by both electrical stimulation and drug administration through pressure microinjection techniques. The head of the cat was first immobilized in a stereotaxic apparatus (David-Kopf, Tujunga, CA, USA). The obex was exposed and was used as the stereotaxic zero. The pressor regions of DM and RVLM, the depressor region of CVLM were located stereotaxically as previously described. ${ }^{15,17}$ A three-barrel micropipette, made from filamented glass ( $1 \mathrm{~mm}$, World Precision Instruments, Inc., Sarasota, Fl, USA) using a vertical puller (PE-2M, Narishige, Tokyo, Japan), was used to approach the brain areas. The tip of the multibarrel pipette, approximately $30 \mu \mathrm{m}$ in diameter, was mounted onto a carrier of the stereotaxic-spinal apparatus (David-Kopf). The pipette was fixed on the stereotaxic carrier at an angle of $34^{\circ}$ and perpendicular to the floor of the fourth cerebral ventricle. One barrel, filled with $3 \mathrm{M} \mathrm{NaCl}$ solution with a platinum wire inserted, served as an electrode for electrical stimulation. 
TABLE I Effects of propofol on electrical stimulation-induced and glutamate-induced changes of arterial blood pressure and heart rate in DM, RVLM and CVLM.

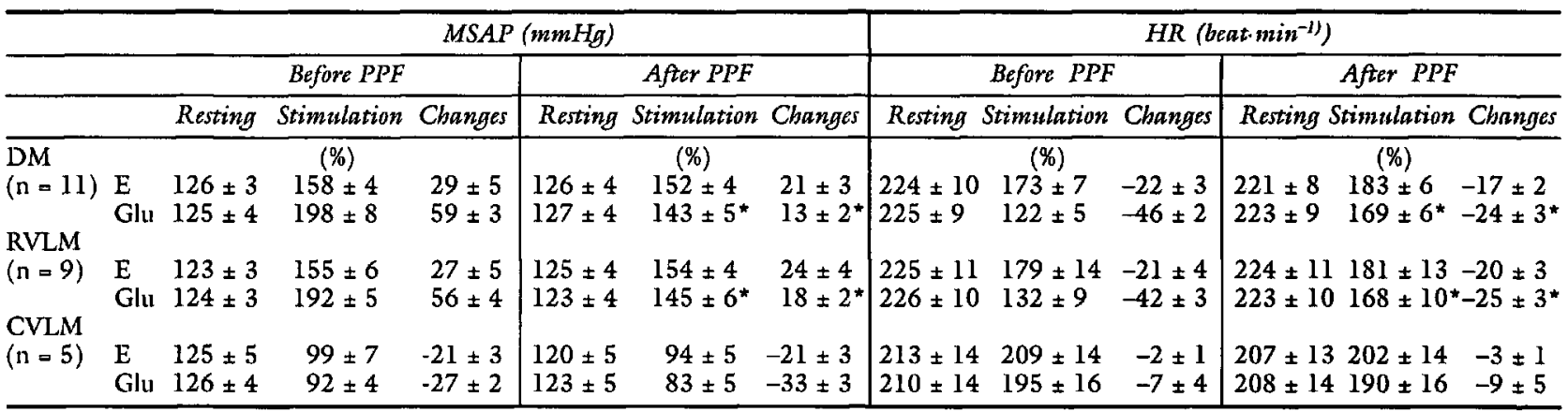

Value are mean \pm SEM

PPF, propofol, DM, dorsomedial $(\mathrm{n}=11)$; VLM, ventrolateral medulla $(\mathrm{n}=9)$; CVLM, caudal ventrolateral medulla $(\mathrm{n}=5$ ); Glu, glutamate; E, clectrical stimulation; MSAP, mean systemic arterial pressure; HR, heart rate; ${ }^{*} P<0.01$ vs control groups.

The stimulation, a 15-sec-constant current of rectangular train pulses ( $5 \mathrm{msec}$ duration, $80 \mathrm{~Hz}, 100 \mu \mathrm{A}$ ), was provided through a constant current unit connected with a rectangular pulses generator (Grass $S$ 88 , Grass Instrument, Ma, USA). The remaining two barrels were filled with either propofol $(0.001 \%)$ or monosodium L-glutamate $(0.25 \mathrm{M})$ dissolved in artificial cerebrospinal fluid at $\mathrm{pH}$ of 7.4 containing pontamine sky blue $1 \%$ (Sigma, St Louis, USA).$^{10}$ Pressure microinjection was performed with pneumatic pumps (Pneumatic Pressure System, Model PPS-2, Medical System, NY, USA).

The cardiovascular-reactive areas in the medulla were functionally identified, first with electrical stimuli and then the presence of a cell body of a neuron was confirmed by microinjection of Glu ( $30 \mathrm{nl}$ in $15 \mathrm{sec}$ ). The cardiovascular responses induced by both electri$\mathrm{cal}$ stimuli and Glu served as controls. One hour after Glu injection, propofol $(0.001 \%, 50 \mathrm{nl})$ or Intralipid $(0.01 \%, 50 \mathrm{nl})$ was microinjected at the same site. Three minutes later, electrical stimulation and Glu were applied again for comparison of changes in SAP, $\mathrm{HR}$ and $d \mathrm{p} / d \mathrm{t}$ with those of the control.

At the end of the experiment, cats were sacrificed with a bolus injection of $\mathrm{KCl}$. Brain sections of $50 \mu \mathrm{m}$ in series were prepared with cryostat (2800 Frigocut E, Reichert-Jung, Germany) and stained for identification of the chemical-injected points marked with pontamine sky blue. All data are presented as mean tstandard error of mean. Paired t test with $P$ value < 0.05 was regarded as statistically significant.

\section{Results}

The actions of propofol on the pressor and depressor areas of the medulla are summarized in Table $I$ and illustrated in Figures 1-4.

\section{Central actions of propofol}

Eight cats were used in this part of the study. The threshold dose of propofol that decreased SAP, MSAP, $\mathrm{HR}$ and $d \mathrm{p} / \mathrm{dt}$ was about $2 \mathrm{mg} \cdot \mathrm{kg}^{-1}$ (Figure $\mathrm{l}$, bottom panel A). At this dose, propofol only produced a transient and slight decrease of SAP and MSAP, but no change of $\mathrm{HR}$ or cardiac contractility. In the absence of propofol, resting MSAP was $155 \mathrm{mmHg}$. It decreased to $145 \mathrm{mmHg}$ after administration of propofol. The action of propofol only lasted for 12 $\mathrm{sec}$. Increasing the dose of propofol to 3 or $4 \mathrm{mg} \cdot \mathrm{kg}^{-1}$ produced a dose-dependent and more marked decreases in MSAP, HR and $d \mathrm{p} / d \mathrm{t}$ (Figure 1, top panels $A$ and $B$ ). The resting MSAP was $140 \mathrm{mmHg}$ and decreased to $105 \mathrm{mmHg}$ by $3 \mathrm{mg} \cdot \mathrm{kg}^{-1}$, and lasted for two minutes. Heart rate was reduced from 260 to 220 bpm. The percent decrease of $d \mathrm{p} / d \mathrm{t}$ was $29 \%$. When $4 \mathrm{mg} \cdot \mathrm{kg}^{-1}$ propofol were applied, MSAP decreased from 140 to $105 \mathrm{mmHg}$ and this suppression lasted more than four minutes. HR was reduced from 290 to $250 \mathrm{bpm}$. The percent decrease of $d \mathrm{p} / d \mathrm{t}$ was $36 \%$. When a smaller dose of propofol $\left(1 \mathrm{mg} \cdot \mathrm{kg}^{-1}\right)$ was injected into the left vertebral artery, a marked decrease of all the above parameters in both extent and duration was observed (Figure 1, bottom panel B). Resting MSAP and HR were $160 \mathrm{mmHg}$ and $250 \mathrm{bpm}$ and decreased to $60 \mathrm{mmHg}$ and 200 bpm, respectively, after propofol. The percent decrease of $d \mathrm{p} / d \mathrm{t}$ was $32 \%$. The depressive effect on MSAP lasted more than $12 \mathrm{~min}$. When $0.5 \mathrm{mg} \cdot \mathrm{kg}^{-1}$ propofol was directly injected into the lateral cerebral ventricle, it produced a greater depressive responses than those induced by the intravenous route with 3 and $4 \mathrm{mg} \cdot \mathrm{kg}^{-1}$ (Figure 1, top panel C vs top panels A and $B$ ) and the actions lasted much longer (50 min). In this cat, resting MSAP and HR were $140 \mathrm{mmHg}$ 


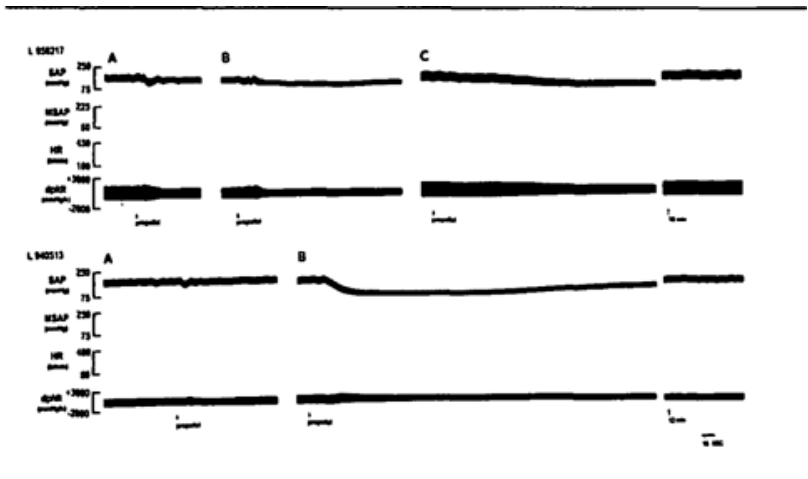

FIGURE 1 Effects of propofol administered via femoral vein, vertebral artery and lateral cerebral ventricle.

In this and the following figures, traces from top to bottom are systemic arterial pressure (SAP), mean systemic arterial pressure (MSAP), heart rate (HR) and cardiac contractility ( $d \mathrm{p} / d \mathrm{t}$ ). Top panels are taken from a cat (950217). Two doses of propofol were administered iv (A: $3 \mathrm{mg} \cdot \mathrm{kg}^{-1} ; \mathrm{B}: 4 \mathrm{mg} \cdot \mathrm{kg}^{-1}$ ). C shows the changes when propofol $\left(0.5 \mathrm{mg} \cdot \mathrm{kg}^{-1}\right)$ was directly injected into the lateral cerebral ventricle. The far right part of panel $\mathrm{C}$ shows the continuation of record $50 \mathrm{~min}$ after the injection of propofol. The bottom panels are taken from another cat (940513). A: when propofol $2 \mathrm{mg} \cdot \mathrm{kg}^{-1} i \mathrm{p}$ was injected and $\mathrm{B}$ : injected into the vertebral artery $\left(1 \mathrm{mg} \cdot \mathrm{kg}^{-1}\right)$. The far right part of panel $B$ shows the continuation of record $12 \mathrm{~min}$ after the injection of propofol.

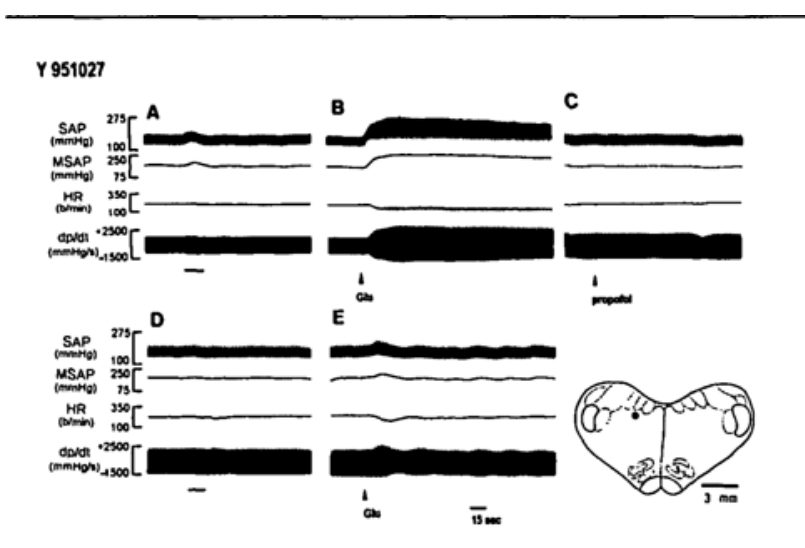

FIGURE 2 Propofol greatly attenuates the responses of dorsomedial medulla (DM) induced by electrical stimulation and glutamate (Glu) from a cat (951027).

Electrical stimuli (panel A, $100 \mathrm{~A}$ ) and Glu (panel B, $30 \mathrm{nl}$ ) were applied to a point in DM. Note that Glu produced a greater increase in SAP of longer duration. One hour later, propofol ( 0.001 $\%, 50 \mathrm{nl}$ ) was applied at the same point (panel C). Three minutes later, electrical stimuli (panel D) and Glu with the same dose (panel E) was then applied at the same point. Note that a marked artenuation of the DM responses in the presence of propofol.

and $240 \mathrm{bpm}$ and decreased to $75 \mathrm{mmHg}$ and 220 bpm, respectively, after propofol. The percent decrease of $d \mathrm{p} / d \mathrm{t}$ was $42 \%$. The solvent itself did not affect any cardiovascular variables when it was admin-

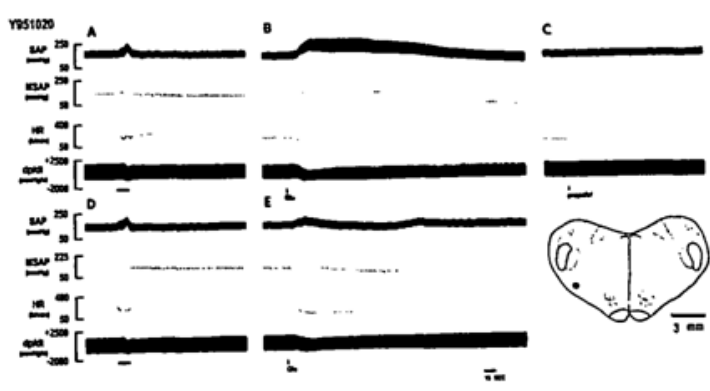

FIGURE 3 Propofol greatly attenuates the pressor responses of rostral ventrolateral medulla (RVLM) induced by electrical stimulation and microinjection of glutamate (Glu) from a cat (951020).

Electrical stimulation (panel A, $100 \mu \mathrm{A}$ ) and Glu (panel B, $30 \mathrm{nl}$ ) were applied to the same point in RVLM. Note the greater increase in SAP with Glu. One hour later, propofol (panel C, 50 $\mathrm{nl)}$ was applied at the same point. Three minutes later, electrical stimuli (panel D, $100 \mu \mathrm{A}$ ) and Glu (panel E, $30 \mathrm{nl}$ ) were applied again. Note that the Glu-induced pressor responses were greatly reduced in the presence of propofol.

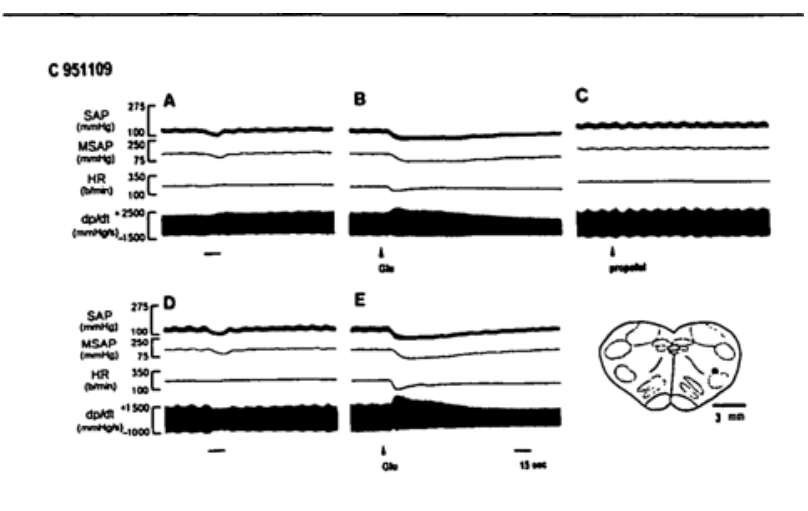

FIGURE 4 Propofol only slightly increases the depressor responses of caudal ventrolateral medulla (CVLM) induced by electrical stimulation and microinjection of glutamate (Glu) from a cat (951109)

Electrical stimulation (panel A, $100 \mu \mathrm{A}$ ) or Glu (panel B, $30 \mathrm{nl}$ ) were applied to a point at CVLM. Note the marked decrease in SAP by Glu. One hour later, propofol (panel C, $50 \mathrm{nl}$ ) was applied at the same site. Three minutes later, electrical stimulation (panel D) and Glu (panel E, $30 \mathrm{nl}$ ) were again applied at the same site. Note that both the electrical and Glu-induced decreases in SAP were slightly but not significatly increased in the presence of propofol.

istered into either the femoral vein, left vertebral artery or left lateral cerebral ventricle (data not shown). The above results suggest that the depressant actions of propofol on cardiovascular function were more pronounced when it was injected into the lateral cerebral ventricle. 


\section{Effects of intracerebral microinjection of propofol}

After the central effects of propofol had been determined, a much smaller dose of propofol $(0.001 \%, 50$ $\mathrm{nl}$,) was microinjected into the pressor region of $\mathrm{DM}$ or RVLM or the depressor region of CVLM $(n=25)$. Propofol or the same volume of solvent (Intralipid ${ }^{\mathrm{TM}}$, $0.01 \%$ ) did not produce any change in resting cardiovascular variables. However, in the presence of propofol, the magnitude of the Glu-induced cardiovascular responses in the two pressor regions (DM and RVLM) were attenuated. (Table I and Figures 2,3 ). In contrast, propofol did not affect the responses induced by electrical current in these two regions (Table I and Figures 2,3 ). On the other hand, propofol slightly, but insignificantly, increased the Glu-induced depressant actions on SAP and HR in CVLM, (Table I, and Figure 4). In these regions of the medulla, the solvent did not change any cardiovascular response induced by electrical current or Glu (data not showed, $n=3$ ).

In the present experiment, we avoided using current of high intensity for stimulation and, thus, responses on stimulating the pressor and depressor areas were smaller than those of Glu. Also, in a few instances, stimulation of CVLM, both with electrical current and Glu increased $d \mathrm{p} / d \mathrm{t}$ against the fall of SAP and HR.

\section{Discussion}

The present study showed that propofol produced more pronounced cardiovascular depression when it was given into the vertebral artery or the lateral cerebral ventricle than when administered via a peripheral vein. The central actions of propofol were further substantiated by the observation that direct microinjection of propofol, in a smaller dose, into the pressor $D M$ and RVLM antagonized their Glu-induced pressor actions. Besides, propofol slightly though not significantly, increased the Glu-induced depressor actions in the depressor CVLM.

Previous studies have shown that propofol exerts many depressant actions in the central nervous system, e.g., changes in electroencephalogram, glucose utilization, sympathetic activity and cerebral blood flow. ${ }^{18-20}$ However, It was also reported that, in the RVLM of rats, the effect of cardiovascular depression induced by glycine was attenuated by propofol. ${ }^{8,9}$ The cellular mechanisms of propofol remain unclear. For example, it has been suggested that propofol may potentiate chloride current activated by $\mathrm{GABA}^{21-23}$ and therefore results in an inhibitory action. It also has been reported that propofol inhibits N-methyl-Daspartate (NMDA) receptor in cultured hippocampal neurons. ${ }^{24}$ Results of our present in vivo experiment show that propofol inhibited the Glu-induced vasomotor action not only in the RVLM but also in the DM. The latter structure has been shown repeatedly to contain neuronal cell bodies sharing vasomotor integration. $10,11,16,17,25,26$

The vasomotor mechanism in the medulla is important for the integration and maintenance of vasomotor tone, and stability of the whole cardiovascular system. ${ }^{10,11,25}$ Regions in the DM, RVLM and CVLM integrate sympathetic outflow. Electrical stimulation and chemical stimulation (e.g., Glu) of both the pressor DM and RVLM increased systemic blood pressure, cardiac contractility and sympathetic nerve activity. ${ }^{10,15,17,26}$ Stimulation of the depressor CVLM, in contrast, elicited the opposite effect ${ }^{25}$ of sympathetic inhibition. ${ }^{27}$ Electrical stimulation activates all components of a neuron, i.e., dendrites, cell body (perikarya) and axons, while chemicals like Glu excite dendrites and cell body, rarely on axon and thus spare passing fibres. ${ }^{28} \mathrm{We}$ intentionally compared the effect of propofol on the cardiovascular responses induced by both electrical stimulation and Glu. Propofol only affects the Glu-induced responses of the pressor DM or RVLM. Actions of propofol on CVLM are mild. Thus, propofol acts mainly on receptors of neuronal cell bodies, in DM and RVLM to effect hypotension.

Propofol was prepared in a solvent (Intralipid ${ }^{\mathrm{TM}}$ ). The hypotensive effects of propofol was not related to this solvent, as control injections of this solvent in the same volume in each route of administration did not produce any action. Therefore, the solvent itself should not influence the results. Since we used very small volumes ( $<50 \mathrm{nl})$ and low speed microinjection, the mechanical effects during pressure injection should be insignificant. In this study, we anaesthetized cats with $\alpha$-chloralose and urethane which has been used routinely for years in our laboratory in the study of cardiovascular regulation in medulla, ${ }^{10,15,17,26}$ a caudal axis of the central nervous system, which is less affected by anaesthetics than that of the rostral axis. The responses induced by medullary stimulation in cats anaesthetized with $\alpha$-chloralose and urethane are as active as those unanaesthetized-decerebrate cats (decerebrate under halothane inhalation and terminate the inhalation afterward).

Propofol has been commonly used in clinical practice. Although regarded as a safe agent, dose-dependent hypotension may occur in certain circumstances, such as in cardiovascular compromising situation, elderly patients or even in young healthy patients. Many hypotheses have been proposed to contribute to 
this side effect. The peripheral mechanisms such as vasodilatation, ${ }^{2,3}$ negative chronotropic and inotropic actions have been well investigated. ${ }^{6,7}$ However, the central mechanism has not been well examined. It has been reported that the cardiovascular responses induced by glycine in pontine reticular formation and ventrolateral medulla in rats could be attenuated by peripheral administration of propofol. ${ }^{8,9}$ In our study, instead of intravenous injection, we directly applied propofol in the cardiovascular-reactive regions of the medulla. The exact cellular mechanisms responsible for its actions on medullary neurons, however, need further investigation.

In conclusion, propofol decreases the Glu-induced pressor actions when directly microinjected into the DM and RVLM. These central actions may contribute to the hypotensive effects of propofol in additional to its peripheral actions.

\section{Acknowledgments}

The authors express their gratitude to Academia Sinica and Tri-Service General Hospital for their kind support. J.J. Pan is also acknowledged for her secretarial help. Thanks are due to Professor Dr. S.H. Ngai from Columbia University (New York) in editing this paper. This study was financially supported in parts by the Foundation of Biomedical Sciences, Shih-Chun Wang Memorial Fund and the National Science Council (No. NSC85-2331-B001-37), Taipei, R.O.C.

\section{References}

1 Peacock JE, Lewis RP, Reilly CS, Nimmo WS. Effect of different rates of infusion of propofol for induction of anaesthesia in elderly patients. Br J Anaesth 1990; 65: 346-52.

2 Bentley GN, Gent JP, Goodchild CS. Vascular effects of propofol: smooth muscle relaxation in isolated veins and arteries. J Pharm Pharmacol 1989; 41: 797-8.

3 Goodchild CS, Serrao JM. Cardiovascular effects of propofol in the anaesthetized dog. Br J Anaesth 1989; 63: 87-92.

4 Sellgren J, Ejnell $H$, Elam M, Pontén J, Wallin BG. Sympathetic muscle nerve activity, peripheral blood flows, and baroreceptor reflexes in humans during propofol anesthesia and surgery. Anesthesiology 1994; 80: 534-44.

5 Ebert TJ, Muzi M. Propofol and autonomic reflex function in humans. Anesth Analg 1994; 78: 369-75.

6 Park WK, Lynch C III. Propofol and thiopental depression of myocardical contractility. A comparative study of mechanical and electrophysiologic effects in isolated guinea pig ventricular muscle. Anesth Analg 1992; 74: 395-405.
7 Tang C-Y, Wong C-S, Yu C-C, Luk H-N, Lin C-I. Propofol inhibits cardiac L-type calcium current in guinea pig ventricular myocytes. Anesthesiology 1996; 84: 626-35.

8 Krassioukov $A V$, Gelb $A W$, Weaver LC. Action of propofol on central sympathetic mechanisms controlling blood pressure. Can J Anaesth 1993; 40: 761-9.

9 Krassioukov $A V$, Gelb AW, Weaver LC. Actions of propofol on pontine neurons controlling arterial pressure in rats. Can J Anaesth 1995; 42: 150-7.

10 Chai CY, Lin RH, Lin AMY, Pan CM, Lee EHY, Kuo $J S$. Pressor responses from electrical or glutamate stimulations of the dorsal or ventrolateral medulla. Am J Physiol 1988; 255: R709-17.

11 Calaresu FR, Yardley CP. Medullary basal sympathetic tone. Ann Rev Physiol 1988; 50: 511-24.

$12 K u b o$ T, Kibara $M$. N-Methyl-D-aspartate receptors mediate tonic vasopressor control in the caudal ventrolateral medulla of the rat. Brain Res 1988; 451: 366-70.

13 Guertzenstein PG. Blood pressure effects obtained by drugs applied to the ventral surface of the brain stem. J Physiol 1973; 229: 395-408.

14 Willette RN, Krieger AJ, Barcas PP, Sapru HN. Medullary $\gamma$-aminobutyric acid (GABA) receptors and the regulation of blood pressure in the rat. J Pharmacol Exp Ther 1983; 226: 893-9.

15 Chen SY, Wang SD, Cheng CL, Kuo JS, De Groat WC, Chai Cr. Glutamate activation of neurons in CV-reactive areas of cat brain stem affects urinary bladder motility. Am J Physiol 1993; 265: F520-9.

16 Chai CY, Wang SC. Mechanisms of sinus bradycardia induced by veratrum alkaloids-protoveratrine A. J Pharmacol Exp Ther 1966; 154: 546-57.

17 Chai CY, Lin $A M Y$, Su CK, et al. Sympathoadrenal excitation and inhibition by lower brainstem stimulation in cats. J Auton Nerv Syst 1991; 33: 35-46.

18 Glen JB. Animal studies of anaesthetic activity of ICI 35 868. Br J Anaesth 1980; 52: 731-41.

19 Dam M, Ori C, Pizzolato G, et al. The effects of propofol anesthesia on local cerebral glucose utilization in the rat. Anesthesiology 1990; 73: 499-505.

20 Van Hemelrijck J, Fitch W, Mattbeussen M, Van Aken $H$, Plets $C$, Lauwers $T$. Effect of propofol on cerebral circulation and autoregulation in the baboon. Anesth Analg 1990; 71: 49-54.

21 Hara $M$, Kai $\Upsilon$, Ikemoto $\Upsilon$. Propofol activates GABA $_{\mathrm{A}}$ receptor-chloride ionophore complex in dissociated hippocampal pyramidal neurons of the rat. Anesthesiology 1993; 79: 781-8.

22 Sanna E, Mascia MP, Klein RL, Whiting PJ, Biggio G, Harris RA. Actions of the general anesthetic propofol on recombinant human $\mathrm{GABA}_{\mathrm{A}}$ receptors: influence of 
receptor subunits. J Pharmacol Exp Ther 1995; 274: 353-60.

23 Sanna E, Garau F, Harris RA. Novel properties of homomeric Bl $\gamma$-aminobutyric acid type $A$ receptors: actions of the anesthetics propofol and pentobarbital. Mol Pharmacol 1995; 47: 213-7.

24 Orser BA, Bertiik M, Wang L-Y, MacDonald JF Inhibition by propofol $(2,6 \mathrm{di}$-isopropylphenol) of the $\mathrm{N}$-methyl-D-aspartate subtype of glutamate receptor in cultured hippocampal neurones. Br J Pharmacol 1995; 116: 1761-8.

25 Dampney RAL. Functional organization of central pathways regulating the cardiovascular system. Physiol Rev 1994; 74: 323-64.

$26 S u$ CK, Lin AMY, Lin RH, Kuo JS, Chai CY.

Contribution between dorsal and ventrolateral regions of medulla oblongata in vasomotor function of cats. Brain Res Bull 1989; 23: 447-56.

27 Cravo SL, Morrison SF. The caudal ventrolateral medulla is a source of tonic sympathoinhibition. Brain Res 1993; 621: 133-6.

28 Lin RH, Lin AMT, Su CK, Kuo JS, Chai CY. Presence of perikarya for vasopressor actions in both the dorsal and ventrolateral regions of medulla oblongata in swine. Neurosci Res Commun 1989; 5: 125-33. 